\title{
Prevalence of Diabetes and Cardiovascular Risk Factors in Ouagadougou (Burkina-Faso)
}

\author{
Rayangnewinde Donald Auguste Yanogo', Yempabou Sagna1, Hervé Tieno1,2, \\ Oumar Guira1,2, Youssouf Joseph Drabo ${ }^{1,2}$ \\ ${ }^{1}$ Departement of Internal Medecine, Centre Hospitalier Universitaire Yalgado Ouedraogo, Ouagadouogou, \\ Burkina-Faso \\ ${ }^{2}$ Health Sciences Training and Research Unit, University of Ouagadougou, Ouagadouogou, Burkina-Faso \\ Email: dyanogo@hotmail.com
}

Received 10 May 2014; revised 13 June 2014; accepted 26 July 2014

Copyright (C) 2014 by authors and OALib.

This work is licensed under the Creative Commons Attribution International License (CC BY). http://creativecommons.org/licenses/by/4.0/

(c) (i) Open Access

\section{Abstract}

Background: Diabetes mellitus is a pathological condition whose worldwide prevalence is growing, particularly in Africa, contrasting with an inadequacy of screening and diagnosis. This study aimed to evaluate the prevalence of this ailment in an urban environment of Burkina-Faso, as well as the prevalence of cardiovascular comorbid risk factors, such as arterial hypertension and obesity. Patients and methods: We conducted a descriptive cross-sectional study based on the compilation of clinical and biological data randomly collected from participants to a diabetes screening day organized at Ouagadougou (Burkina-Faso) in December 2012. Participants aged $<25$ years were excluded. The evaluated parameters were age, gender, waist circumference, body mass index, blood pressure, and random (non) fasting capillary plasma glucose measurement, and presence of a metabolic syndrome. Results: There were overall one hundred and sixty five participants: 107 women and 58 men (sex ratio $F / H=1.84)$. The mean age $( \pm 1$ SD) of participants was $42.81 \pm 11.7$ years. The prevalence of screened diabetes was $7.27 \%$, with a prevalence of undiagnosed diabetes of $4.97 \%$. The prevalence of arterial hypertension was $34.55 \%$. The prevalence of obesity was $15.15 \%$ (obesity class 1 ), $5.45 \%$ (obesity class 2 ) and $1.21 \%$ (obesity class 3 ). About $27 \%$ of women were obese versus $19.44 \%$ of men $(p=0.01)$. The prevalence of metabolic syndrome was $6.06 \%$, and its presence was significantly associated with the female gender $(9.35 \%$ in women vs $0 \%$ in men, $p=0.005) .50 \%$ of subjects screened with diabetes also had a metabolic syndrome versus $2.61 \%$ in non-diabetic subjects $(p<0.01)$. Conclusion: (Un)diagnosed diabetes was highly-prevalent in this urban environment of Burkina Faso undergoing the nutritional transition phase currently prevailing in sub-Saharan Africa. Its presence was significantly co-morbid with the metabolic syndrome, as well as with other major cardiovascular risk factors such as arterial hypertension and obesity. 


\title{
Keywords
}

\author{
Diabetes, Risk Factors, Screening, Urban Environment, Burkina-Faso
}

Subject Areas: Diabetes \& Endocrinology, Epidemiology

\section{Introduction}

Type 2 diabetes mellitus (T2DM) is a common medical condition characterized by chronic hyperglycemia due to a multifactorial disorder of glucose metabolism and relentless $\beta$-cell failure. The prevalence of T2DM is increasing worldwide, and represents a major noncommunicable public health problem. The International Diabetes Federation (IDF) estimated in 2011 that the number of diabetics will increase from 360 million to 550 million in 2030. Furthermore, according to global statistics, the prevalence of diabetes in sub-Saharan Africa may reach 23.9 million in 2030 (vs. 14 million in 2011) [1]. This increase could lead to substantial rises in terms of medical complications as well as in adverse socio-economic impact [2]. The predicted epidemics is all the more worrying since about three-quarters of diabetics in developing countries with low economic level are undiagnosed [3], due to inadequate screening and prevention programs and low affordability of bioassays for screening and diagnosis. In parallel to the diabetes epicemics, there is also a rapid rise in prevalence of the hypertension and obesity, two comorbidities which contribute to increased cardiovascular morbidity and mortality.

The aim of the present survey was to evaluate the prevalence of (un)diagnosed diabetes and major cardiovascular risk factors such as hypertension and obesity in the urban population of Ouagadougou in Burkina Faso. This pilot survey was carried out during a screening day, and aimed at providing data on prevalence that could be used as proxi for unavailable local data from population-based study on these pathologies.

\section{Patients and Methods}

The diabetes screening team conducted a descriptive cross-sectional survey on December 15th, 2012. The study population consisted of the inhabitants of district number 6 of Ouagadougou whose age was $\geq 25$ years. The population of this district number was 317,154 based on the 2006 General Census [4], and about $63 \%$ of these individuals were 15 years-old or more. Participants consisted of volunteers who responded to the screening invitation (relayed through posters and/or town-criers) to participate to a screening day and gave their consent. Each recruited subject was eligible to a review by the medical staff, which consisted of the collection of information on age, gender, occupation, medical history of diabetes and of high blood pressure (hypertension); a clinical assessment consisting of a height measurement (in centimeters), a waist circumference measurement (midway between the iliac crest and the lower edge of the rib cage) with a tape graduated in centimeters, a body weight measurement (in kg using adult EKS ${ }^{\circledR}$ brand scales), a recording of humeral blood pressure (BP), in the sitting position after five minutes of rest (automatic sphygmomanometer MAGNIEN HL888A SAS ${ }^{\circledR}$ ); a biological evaluation by measuring casual capillary blood glucose (CCBG, $\mathrm{mg} / \mathrm{dl}$ ) from a drop of digital blood (using a test strip), followed by testing with a glucose sensor (ARKRAY ${ }^{\circledR}$ Glucocard X-mini plus GT-1960).

Calculation of body mass index $\left(\mathrm{BMI}=\right.$ weight $/$ height $\left.{ }^{2}\right)$ of each participant was used to assess weight status according to the following criteria: $\mathrm{BMI}<18.5 \mathrm{~kg} / \mathrm{m}^{2}$ (underweight); $18.5-24.9 \mathrm{~kg} / \mathrm{m}^{2}$ (normal weight); 25.0 $29.9 \mathrm{~kg} / \mathrm{m}^{2}$ (overweight); 30.0 - $34.9 \mathrm{~kg} / \mathrm{m}^{2}$ (Class I obesity); 35.0 - $39.9 \mathrm{~kg} / \mathrm{m}^{2}$ (Class II obesity); and $\geq 40 \mathrm{~kg} / \mathrm{m}^{2}$ (Class III obesity).

The threshold set for diabetes screening by random capillary plasma glucose (RCPG) was $\geq 140 \mathrm{mg} / \mathrm{dl}$.

Hypertension was defined as systolic blood pressure (SBP) $\geq 140 \mathrm{mmHg}$ and/or diastolic blood pressure (DBP) $\geq 90 \mathrm{mmHg}$, according to the criteria defined by the World Health Organization.

The NCEP-ATP III criteria were used to define the metabolic syndrome (MS) in this population, defining abnormal waist as $>102 \mathrm{~cm}$ (men) and $>88 \mathrm{~cm}$ (women), elevated BP as SBP >130 $\mathrm{mmHg}$ and/or DBP $>85$ $\mathrm{mmHg}$; and dysglycemia/diabetes as glucose $>110 \mathrm{mg} / \mathrm{dl}$.

The data collected on a single collection sheet were computed using Microsoft Office Excel 2007 software. The analysis was performed using Epi Info 7. The significance level for $\mathrm{p}<0.05$ was used for statistical tests. 


\section{Results}

There was a total of 165 participants, whose average age ( \pm 1 SD) was $42.81 \pm 11.7$ years (min-max $25-75$ years), with a sex ratio of 1.84 in favor of women. Patients aged $\geq 40$ years accounted for $55.76 \%$ of the study population.

Average random blood glucose measurement was $96.24 \pm 33.78 \mathrm{mg} / \mathrm{dl}$ [58 - $348 \mathrm{mg} / \mathrm{dl}]$ (Table 1). The overall prevalence of (un)diagnosed diabetes was $7.27 \%(12 / 165$ subjects, CI $=[3.81 \%-12.36 \%])$ regarding the established criteria (Table 1). The prevalence of diabetes was $7.61 \%$ among those aged 40 years or more, and $6.85 \%$ in subjects $<40$ years $(p=0.18) .8 .62 \%$ of men were diabetic vs. $6.54 \%$ of women $(p=0.43)$. Among diabetic subjects, 4 had a history of known diabetes. As a result, the prevalence of unknown diabetes was $4.97 \%$ (8/161 subjects; CI $=[2.17 \%-9.56 \%])$.

Hypertension prevalence was 34.55\% (CI = [27.33\% - 42.33\%]) with a mean SBP of $125.31 \pm 22.61 \mathrm{mmHg}$, and a mean DBP of $78.89 \pm 12.80 \mathrm{mmHg}$ (Table 1). A third of those diagnosed with elevated BP had a known history of hypertension (19/57 subjects), resulting in a $23.03 \%$ prevalence of undiagnosed hypertension. Half of the diabetic subjects were hypertensive vs. $33.33 \%$ of non-diabetic subjects, although such difference did not reach significance level.

Obesity was also frequent in this population, with a prevalence of $15.15 \%$ for Class I obesity, $5.45 \%$ for Class II obesity and $1.21 \%$ for Class III obesity. Approximately $27 \%$ of women were obese against $19.44 \%$ of men (p $=0.01)$. There was no significant difference in the prevalence of obesity in diabetic and non-diabetic subjects (8.33\% vs. 22.88\%, $\mathrm{p}=0.4$ ).

A metabolic syndrome was found in 10 subjects (all women), representing a prevalence of $6.06 \%$ in the whole population $(\mathrm{CI}=[2.94 \%$ - $10.86 \%]$ ). The gender imbalance of MS prevalence was highly significant in this population $(9.35 \%$ of women and $0 \%$ of men; $p=0.005) .50 \%$ of patients diagnosed with diabetes had a MS vs. $2.61 \%$ of non-diabetic subjects $(\mathrm{p}<0.01)$.

\section{Discussion}

Screening for diabetes mellitus in urban population by measuring random capillary plasma glucose represents an alternative to the measurement of venous plasma glucose (fasting or OGTT) because it is easier to perform, less expensive and less invasive although results obtained by this method are likely to be influenced by the level of sensitivity and specificity of the material used [5]. The threshold for such screening at $140 \mathrm{mg} / \mathrm{dl}$ with the method of RCPG that we used in this study can be considered as the one giving the highest level of sensitivity and specificity for the screening of diabetes mellitus [6].

Table 1. Average of analyzed variables and diabetes prevalence, HBP, Obesity.

\begin{tabular}{|c|c|c|}
\hline Variables & Parameters & Results \\
\hline \multirow{3}{*}{ RCPG } & Glycemia Average (mg/dl) & $96.24 \pm 33.78$ \\
\hline & Prevalence IGT (\%) & 9.09; IC = [5.18 - 14.55] \\
\hline & Diabetes Prevalence (\%) & $7.27 ; \mathrm{IC}=[3.81-12.36]$ \\
\hline \multirow{3}{*}{ BP } & SBP Average (mmHg) & $125.31 \pm 22.61$ \\
\hline & DBP Average (mmHg) & $78.89 \pm 12.80$ \\
\hline & HBP Prevalence (\%) & $34.55 ; \mathrm{IC}=[27.33-42.33]$ \\
\hline \multirow{3}{*}{ BMI } & BMI Average $\left(\mathrm{kg} / \mathrm{m}^{2}\right)$ & $26.02 \pm 5.17$ \\
\hline & Overweight Prevalence (\%) & $30.30 ; \mathrm{IC}=[23.40-37.93]$ \\
\hline & Obesity Prevalence (\%) & $21.82 ; \mathrm{IC}=[15.77-28.9]$ \\
\hline \multirow{2}{*}{ WC } & Men Average (cm) & $92.03 ; \mathrm{IC}=[73-125]$ \\
\hline & Women Average (cm) & 93.93; IC = [73 - 131] \\
\hline SM & MS Prevalence (\%) & $6.06 ; \mathrm{IC}=[2.94-10.86]$ \\
\hline
\end{tabular}

RCPG = Random Capillary Plasma Glucose; BP = Blood Pressure; SBP = Systolic Blood Pressure; DBP = Diastolic Blood Pressure; BMI = Body Mass Index; WC = Waist Circumference; MS = Metabolic Syndrome; IGT = Impaired Glucose Tolerance; HBP = Hypertension. 
The fact that it was not feasible to perform confirmatory measurement of fasting plasma glucose in patients diagnosed with diabetes-range hyperglycaemia to fully meet the diagnostic criteria for diabetes is a limitation of this pilot survey, as is the sample size of individuals who participated to the screening. Given the total population of district 6, the present prevalence figures represent useful approximations in need of confirmation, with inherent estimation bias.

The overall prevalence of diabetes recorded in this survey was $7.27 \%$. Compared with prevalence data from the sub-region, we found that our figures are greater than the 3.3\% prevalence reported in 2009 by Djorolo et al. from Cotonou [7], while closer to the 7.7\% prevalence recorded in urban areas by Balde et al. in Guinea in 2007 [8], and the 7.6\% prevalence observed in the African subgroup of the Interheart study in 2005 [9]. However, it is significantly lower than the $17.9 \%$ prevalence observed in Dakar by Duboz [10] in 2012. Our estimation may be somewhat biased by the participants motivation and characteristics to undergo volunteer screening. Nevertheless, it seems likely that diabetes prevalence is on the increase in urban areas of sub-Saharan Africa compared to the much lower previous 1.1\% prevalence recorded in Dakar in 1960 by Payet et al. [11].

We found a worryingly-high proportion of undiagnosed diabetes among the volunteers screened with hyperglycaemia (8/12 or $66.66 \%)$. This proportion is higher than that reported by Balde et al. from Guinea in 2007 from urban areas (59\%) [8], suggesting a major unmet need of screening for diabetes and other cardiometabolic states in urban areas of Burkina-Faso.

The significant association between the presence of diabetes mellitus and the presence of metabolic syndrome in this survey was not unexpected, as most cases of diabetes represent the common form of T2DM, itself strongly comorbid to the MS, through acquired insulin resistance/hyperinsulinaemia and central obesity [12]. It is increasingly recognized that such association, increasingly common, is largely driven by the epidemics of obesity related to changes in human lifestyle over the past few decades (including changes in caloric intake and composition, food security, sedentarity, and decreased work/leisure-time physical activity) particularly in industrialized countries. The same trend is observed today in developing countries, especially in urban environments [13] [14]. However, we did not observe any significant association between the presence of obesity (by BMI or by waist circumference) and the diabetes prevalence in this survey, in line with the observations of ZABSONRE et al. who found no significant associations between obesity and diabetes in Burkina-Faso in 2000 [15].

Obesity was significantly more frequent among female subjects who participated in this survey (27.1\%), slightly less than the 33\% figure observed in 2010 by Nono et al. in adult women from Cameroon [16]. More than $60 \%$ of obese subjects were women in the studies of Ndiaye-Badiane et al. [17]. The high prevalence of obesity among urban women in sub-Saharan Africa is often ascribed to changes in lifestyles, and also related to adverse socio-cultural factors such as lack of awareness of cardiometabolic risk factors due to low level of education, but also to the culturally-positive perception of many women (and men) that overweight and obesity are linked to favourable socio-economic status.

Hypertension (HBP) was also common in this study (34.55\%) but no significant association was found between hypertension and prevalent diabetes. The prevalence of hypertension in this survey was lower than the 40.2\% figure found by Niakara et al. in Ouagadougou in 2007 [18]. However, there seems to exist a marked increase in hypertension prevalence in Ouagadougou, based on observations made in 2003 by Niakara et al. of a 23\% HBP prevalence in this town [19]. Such a rising trend is likely related as well to changes in lifestyles within the overall framework of growing urbanization and sedentarity.

\section{Conclusion}

The present survey confirms that diabetes in urban areas is surging in developing countries such as BurkinaFaso, especially in urban environments which are increasingly considered as diabetogenic. Diabetes prevalence is significantly associated with that of the metabolic syndrome, as well as with a high prevalence of major cardiovascular risk factors such as hypertension and in obesity, in the setting of the nutrition transition prevailing in sub-Saharan Africa. The rapid growth in diabetes mellitus prevalence and cardiovascular risk factors in developing countries, and in sub-Saharan Africa in particular, represents a growing challenge for individuals, communities, health care providers and for all medical, political and economical players. There is an urgent and unmet need, in addition to strengthening prevention programs, for a more thorough evaluation of the current epidemics on a local scale, to better plan and implement interventions, in terms of training of skilled health workers, infrastructures and acquisition of medicines and equipments for proper care of patients to achieve optimal control of this preventable public health problem. 


\section{Conflict of Interest}

The authors reported no conflicts of interest.

\section{References}

[1] International Diabetes Federation (2011) Diabetes Atlas. 5th Edition, International Diabetes Federation, Brussels.

[2] Gning, S.B., Thiam, M., Fall, F., Ba-Fall, K., Mbaye, P.S. and Fourcade, L. (2007) Le diabète sucré en Afrique subsaharienne: Aspects épidémiologiques, difficultés de prise en charge. Med Trop., 67, 607-611.

[3] Mbanya, J.C., Motala, A.A., Sobngwi, E., et al. (2010) Diabetes in Sub-Saharan Africa. Lancet, 375, 2254-2266. http://dx.doi.org/10.1016/S0140-6736(10)60550-8

[4] Commune de Ouagadougou, Directions des études et de la planification, Annuaire statistique 2010.

[5] Puavilai, G., Kheesukapan, P., Chanprasertyotin, S., Chantraraprasert, S., Suwanvilaikorn, S., Nitiyanant, W., et al. (2001) Random Capillary Plasma Glucose Measurement in the Screening of Diabetes Mellitus in High-Risk Subjects in Thailand. Diabetes Research and Clinical Practice, 51, 125-131. http://dx.doi.org/10.1016/S0168-8227(00)00223-0

[6] Somannavar, S., Ganesan, A., Deepa, M., et al. (2009) Random Capillary Blood Glucose Cut Points for Diabetes and PreDiabetes Derived from Community-Based Opportunistic Screening in India. Diabetes Care, 32, 641-643. http://dx.doi.org/10.2337/dc08-0403

[7] Djrolo, F. (2009) Prévalence du diabète sucré dans une population urbaine en milieu africain à Cotonou (Bénin). Diabetes \& Metabolism, 35, A53. http://dx.doi.org/10.1016/S1262-3636(09)71903-2

[8] Balde, N.M., Diallo, I., Balde, M.D., et al. (2007) Diabetes and Impaired Fasting Glucose in Rural and Urban Populations in Futa Jallon (Guinea): Prevalence and Associated Risk Factors. Diabetes \& Metabolism, 33, 114-120. http://dx.doi.org/10.1016/j.diabet.2006.10.001

[9] Steyn, K., Sliwa, K., Hawken, S., et al. (2005) Risk Factors Associated with Myocardial Infarction in Africa: The INTERHEART Africa Study. Circulation, 112, 3554-3561. http://dx.doi.org/10.1161/CIRCULATIONAHA.105.563452

[10] Duboz, P., et al. (2012) Prevalence of Diabetes and Associated Risk Factors in a Senegalese Urban (Dakar) Population. Diabetes \& Metabolism, 38, 332-336. http://dx.doi.org/10.1016/j.diabet.2012.02.011

[11] Payet, M., Sankale, M., Pene, P., et al. (1960) The Chief Aspects of Diabetes Mellitus in an African Environment at Dakar. Bulletin de la societé de pathologie exotique et de ses filiales, 53, 901-910.

[12] Hermans, M.P. and Buysschaert, M. (2004) Prévalence et caractéristiques cliniques de sujets diabétiques de type 2 en fonction de la présence d'un syndrome métabolique selon les critères ATPIII. Diabetes \& Metabolism, 30, 104.

[13] Colin, I.M. (2005) Obésité, syndrome métabolique et diabète: les complices désignés d’une épidémie d’un genre nouveau. Louvain Medical, 124, S7-S10.

[14] Popkin, B.M. (2004) Diabète et société: Transition nutritionnelle et évolution mondiale vers l'obésité. Diabetes Voice, 49, 38-40.

[15] Zabsonre, P., Sedogo, B., Lankoande, D. and Dyemkouma, F.X. (2000) Obésité et maladies chroniques en Afrique subsaharienne. Médecine d'Afrique Noire, 47, 5-9.

[16] Nono, C., Fokumlah, P., Sab Fru, C., Sobngwi, E. and Kengne, P. (2010) PP13: Prévalence de l'obésité chez les femmes adultes en milieu urbain en Afrique sub-saharienne: le cas de Limbé au Cameroun. Résumés des communications de la réunion scientifique de la SFD et de la SFD Paramédical. Diabetes Metab., 36, 13.

[17] Ndiaye-Badiane, F. (2003) Prise en charge décentralisée du diabète sucré (Bilan de la première année au centre de santé Nabil Choucair). Thèse Med Dakar.

[18] Niakara, A., et al. (2007) Hypertension, Urbanization, Social and Spatial Disparities: A Cross-Sectional PopulationBased Survey in a West African Urban Environment (Ouagadougou, Burkina Faso). Transactions of the Royal Society of Tropical Medicine and Hygiene, 101, 1136-1142. http://dx.doi.org/10.1016/j.trstmh.2007.07.002

[19] Niakara, A., et al. (2003) Connaissances d'une population urbaine sur l'hypertension artérielle: enquête prospective menée à Ouagadougou (Burkina Faso). Bulletin de la société de pathologie exotique, 96, 219-222. 